\title{
TO DETERMINE THE LEVEL OF SATISFACTION AMONG PATIENTS REGARDING QUALITY OF MEDICAL SERVICES BEING PROVIDED AT PAF HOSPITAL RAFIQUI AND TO DEVELOP SUGGESTIONS FOR BETTER PATIENT CARE
}

\author{
MUHAMMAD TAHIR SHAH ${ }^{1}$, AMER NADEEM $^{2}$, MUHAMMAD ALI $^{3}$, JUNAID ALAM $^{4}$, \\ MUHAMMAD ILYAS ${ }^{5}$, AAMER AYUB ${ }^{5}$ \\ ${ }^{1}$ PAF base Rafiqui, ${ }^{2}$ Department of ENT, Nishtar medical university, ${ }^{3} \mathrm{PAF}$ hospital E9 Islamabad, ${ }^{4} \mathrm{PAF}$ hospital \\ Mianwale, ${ }^{5}$ Department of ENT, Postgraduate Medical Institute/Ameer ud Din Medical College/Lahore General \\ hospital, Lahore.
}

\begin{abstract}
Objectives: To identify the problem areas and towards developing suggestions for better patient care. To determine level of satisfaction among patients regarding quality services being provided at hospital.

Methods: Study design is cross sectional. Hundred indoor and hundred outdoor patients were selected for a period of about 2 months. Data was collected and analyzed by using statistical software SPSS 20.

Results: A total of 200 patients were selected in this study, 100 indoor patients and 100 outdoor patients. Of these 200 patients, $102(51 \%)$ were male patients while $98(49 \%)$ were female patients. Mean age of our study cases was $39.08 \pm$ 15.33 years, $110(55 \%)$ were from rural areas while $90(45 \%)$ were from urban areas, $129(64.5 \%)$ were literate and 105 $(52.5 \%)$ were satisfied from the quality of the services being provided. Among indoor patients most unsatisfying point was behavior of nursing staff and among out door patients most unsatisfying point was long waiting time.
\end{abstract}

Key words: - satisfaction; patient care; quality.

How to cite this article: Shah MT, Nadeem A, Ali M, Alam J, Ilyas M, Ayub A. To determine the level of satisfaction among patients regarding quality of medical services being provided at PAF hospital Rafiqui and to develop suggestions for better patient care. Pak Postgrad Med J 2020;31(1): 7-12

This is an Open Access article distributed under the terms of the Creative Commons Attribution License (http://creativecommons.org/licenses/by/3.0), which permits unrestricted use, distribution, and reproduction in any medium, provided the original work is properly cited.

DOI: HTTPS//DOI.ORG/10.51642/ppmj.v31i01.327

\section{INTRODUCTION}

Quality is a very complex term and each field of life defines it according to its needs and requirements.

In Health care setup it consists of affective, efficient accessible, acceptable, patient centered, equitable and safe $^{1}$. In health care system of armed forces there are large and small medical setups. Class C and D military hospitals, in case of armed forces are normally established at remote areas for soldiers in combat situation near the front. These setups receive mostly emergencies, being closed to combat zone. In these situations, the quality should be speedy and efficient of health system. Another important quality matter is availability of the medicines which are required to save the patients.
There are few determinants of quality which are common for all medical setups, no matter if it is large or small. Five major characteristic of medical service quality were investigated by kasper, Helsdingen and Gabbott viz, tangibility, assurance, reliability empathy and responsiveness ${ }^{2}$. Determinants like reliability, assurance and empathy are important in case of small medical setups.

In peripheral class $C$ and $D$ military hospital patients are vulnerable for compromised health care system due to inadequate health resources and long referral time to tertiary care facilities. Physicians and paramedical staff also usually have less service and experience. This makes the patient vulnerable to medical hazards. Satisfaction and safety of patient are important factors 
in quality of health care. Medical staff has a prime role in patient satisfaction.

Peter Johansson and coworkers (2002) considered it important to check out the level of patient satisfaction with performance of nursing staff. They investigated effect of nursing care on patient satisfaction by using the Henderson's nursing model. Their results showed that patient expectations with nursing staff, socio demographic back ground of patient physical environment participation and involvement, communication and information, medical technical skills of nursing staff and inter personal relations between patient and nursing staff were important domains that affect the level of patient satisfaction ${ }^{3}$.

M. Robina and co-researches (1980) investigated the effect of nonverbal abilities to communicate with patients, on the patient satisfaction. They made two groups of patients and performance of doctor was judged upon, rating they received from patients, depending upon their technical competence and art of medical care. They found that physicians those were good communicators with good technical ability, were effectively able to satisfy the patients ${ }^{4}$.

KD Rao, DH peters and K Bandeen-Roche (2006) conducted a study to establish patient centered health care system. They found that in care of inpatient the behavior of staff has the lager effect upon the patient satisfaction. Other domains like doctor attitude, availability of medicine, medical education and hospital infrastructure follows in descending order of effectiveness. For outpatient, however attitude of doctor was the prime factor of patient satisfaction. Other factors like availability of medicine infrastructure of hospital and behavior of staff followed in descending order of effectiveness 5 .

Vida Francis and coworkers (1969) carried out a study to check out the flaws in communication between doctor and patient. They purposed the expectation of warmth behavior from doctor at the end of patients. They found that lack of warmth behavior from doctors resulted in dissatisfaction in patients ${ }^{6}$.

Syed saad Andaleeb (2001) carried out a survey in different hospitals to investigate the relationship between patient satisfaction and service quality. He conducted patient centered study. The study was based upon the domain like responsiveness, discipline, assurance, and communication. Results indicated the noteworthy link between these domains with patient satisfaction ${ }^{7}$.

PAF hospital Rafiqui is situated in remote area of shorkot district Jhang Punjab. It is a 100 bedded hospital, and it provides health care facility not only to Pakistan air force employs but also to army, navy and civilian patients of its surrounding. In this way it covers a huge area as there is no other proper health care facility in its surrounding till Multan on one side and Faisalabad or Lahore on the other side. It has a qualified Surgical specialist, two Medical specialists, two Gynecologists, one Child specialist, one ENT, one EYE, one Pathologist, one Radiologist, one Anesthetist and seven general duty Medical officers. They all take part in round the clock duties and emergencies. At the same time on the other end, hospital has some limitations; it has no Cardiologist, Orthopedic surgeon, Neurosurgeon, Psychiatrist and other specialties. Which create problem in the treatment of patients in some emergency situation.

Despite initiating multiple measures to address human resource and infrastructure development, meeting client expectation appear to be far from satisfaction. Still deficient human resource along with exponential increase in clientele is one of the causes of delayed processes in almost all departments. In this scenario conducted a small study here at PAF Hospital Rafiqui to find out the problem areas for the patients coming to attend the hospital.

In this study, we selected 100 patients from out door and 100 patients from indoor. A questionnaire was developed in this context circulated, data was collected and analyzed.

\section{METHODS}

This cross - sectional study was done at Pakistan air force hospital Rafiqui Shorkot using non - probability convenient sampling technique. All patients coming to OPD and indoor patients in the hospital were included in this study after taking informed verbal consent. Total 200 patients (100 OPD and 100 indoor patients). A predesigned questionnaire was used to record the findings of the study and was analyzed by using SPSS -20 .

\section{RESULTS}

At the end of collection of data following result were obtained. A total of 200 patients were selected in this study, with 100 indoor patients and 100 outdoor patients. Of these 200 patients, $102(51 \%)$ were male patients while 98 (49\%) were female patients. Mean age of our study cases was $39.08 \pm 15.33$ years, $110(55 \%)$ were from rural areas while $90(45 \%)$ were from urban areas, $129(64.5 \%)$ were literate and $105(52.5 \%)$ were satisfied from the quality of the services being provided. Hundred admitted patients were selected, and it was found that out of the 100 patients, 47 patients were not satisfied. Out of these 30 patients were not satisfied with behavior of nursing staff. According to patients they were not attending their complaints with interest. 12 
patients complained about the dirty bed sheets and uncleanliness of the ward and 5 patients complained about the medications, that they were not satisfied about the type of medication.

Hundred outdoor patients were selected. Out of 100 patients 48 patients complained about different sections. 25 patients complained about the long waiting time, 10 patients complained about the behavior of the doctor, 5 about limited laboratory facility, 5 about the medical store that it is not available round the clock and 3 about quality of medication available.

Table No. 1 Cross - tabulation of level of satisfaction with regards to gender.

$(\mathrm{n}=200)$

\begin{tabular}{cccc}
\hline \multirow{2}{*}{ Gender } & \multicolumn{2}{c}{ Level of satisfaction } & \\
\cline { 2 - 3 } & $\begin{array}{c}\text { Satisfied } \\
(\mathrm{n}=105)\end{array}$ & $\begin{array}{c}\text { Un - satisfied } \\
(\mathrm{n}=95)\end{array}$ & $\mathrm{P}$ - value \\
\hline $\begin{array}{c}\text { Male } \\
(\mathrm{n}=102)\end{array}$ & 53 & 49 & \\
$\begin{array}{c}\text { Female } \\
(\mathrm{n}=98) \\
\text { Total }\end{array}$ & 52 & 46 & 0.888 \\
\hline
\end{tabular}

Table No. 2 Cross - tabulation of level of satisfaction with regards to residential status.

$(\mathrm{n}=200)$

\begin{tabular}{|c|c|c|c|}
\hline \multirow[b]{2}{*}{$\begin{array}{l}\text { Residential } \\
\text { status }\end{array}$} & \multicolumn{2}{|c|}{ Level of satisfaction } & \multirow[b]{2}{*}{$\begin{array}{c}\mathrm{P} \text { - } \\
\text { value }\end{array}$} \\
\hline & $\begin{array}{c}\text { Yes } \\
(\mathrm{n}=105)\end{array}$ & $\begin{array}{c}\text { No } \\
(\mathrm{n}=95)\end{array}$ & \\
\hline $\begin{array}{c}\text { Rural } \\
(\mathrm{n}=110)\end{array}$ & 68 & 42 & \\
\hline $\begin{array}{l}\text { Urban } \\
(\mathrm{n}=90)\end{array}$ & 37 & 53 & 0.004 \\
\hline Total & \multicolumn{2}{|c|}{200} & \\
\hline
\end{tabular}

Table No. 3 Cross - tabulation of level of satisfaction with regards to educational background.

$(\mathrm{n}=200)$

\begin{tabular}{cccc}
\hline & \multicolumn{2}{c}{ Level of satisfaction } & \\
\cline { 2 - 3 } Education & $\begin{array}{c}\text { Satisfied } \\
(\mathrm{n}=105)\end{array}$ & $\begin{array}{c}\text { Un - } \\
\text { satisfied } \\
(\mathrm{n}=95)\end{array}$ & P - value \\
\hline $\begin{array}{c}\text { Literate } \\
(\mathrm{n}=129)\end{array}$ & 51 & 78 & \\
$\begin{array}{c}\text { Illiterate } \\
(\mathrm{n}=71) \\
\text { Total }\end{array}$ & 54 & 17 & 0.000 \\
\hline
\end{tabular}

\section{DISCUSSION}

From the result it has been cleared that things which affect the satisfaction level of indoor patients are nursing staff behavior and their interest in their work, cleanliness of the ward and the medication of the patients. These areas of patient care are more important in indoor patient care. While in outdoor patient department patients were not satisfied due to long waiting time, behavior of doctors, laboratory and medical store facilities are not available round the clock and the type of medication is not up to the mark. It has seen that these are the problem areas in almost all medical setups and it's important to convey this knowledge at all levels to produce orientation in para medical staff and doctors for betterment of the system.

\section{RECOMMENDATIONS:}

- First of all, it's very important to generate idea of patient satisfaction in the health care providers. For this discussion of this point at morning assembly can create better environment.

- Nursing staff working in the wards should be advised on regular bases to provide better care to the patient and staff working better in the wards should be encouraged.

- Cleanliness of wards creates good impression on patients it should be checked on daily basis.

- Patients complaints should be sort out on early basis for creating good environment. Complaint desk should be established for this purpose.

- Doctors with good attitude towards patients should be given priority at OPD level and they should be encouraged.

- Number of doctors and para medical staff should be increased at busy places.

- Session of medical education and training for doctors and paramedical staff should be arranged for improving the situation.

\section{ETHICAL APPROVAL}

The study was approved by the Ethical Review Committee of Military Hospital, Rawalpindi, dated September, 2020.

\section{REFERENCES}

1. Organization, W.H. (2006), Quality of care; a process for making strategic choices in health system.

2. kokou P, Tonder EV, Lorrbard MR. Patient satisfaction measurement for in hospital services delivered by nurses: Guidelines for improving practice in Africa. Am J Health Sci. 2015;6(1):23-36.

3. Johansson P, Oléni M, Fridlund B. Patient satisfaction with nursing care in the context of health care: a literature study. Scand J Caring Sci. 2002 Dec;16(4):337-344. 
4. DiMatteo MR, Hays RD, Prince LM. Relationship of physicians' nonverbal communication skill to patient satisfaction, appointment noncompliance, and physician workload. Health Psychol. 1986;5(6):581-594.

5. Rao KD, Peters DH, Bandeen-Roche K. Towards patientcentered health services in India--a scale to measure patient perceptions of quality. Int J Qual Health Care. 2006 Dec;18(6):414-21. Epub 2006 Sep 29.

6. Francis V, Korsch BM, Morris MJ. Gaps in doctorpatient communication. Patients' response to medical advice. N Engl J Med. 1969 Mar 6;280(10):535-540.

7. Andaleeb SS. Service quality perceptions and patient satisfaction: a study of hospitals in a developing country. Soc Sci Med. 2001 May;52(9):1359-1370.

\section{AUTHORS' CONTRIBUTION:}

MTS: Conceived, designed, manuscript writing AN: Supervision and contribution in manuscript writing

MA: Critical Review

JA: Data Collection

MI: Review \& suggestions

AA: Data analysis 